March 2014

\title{
Retinopathy of prematurity: an evaluation of existing screening criteria in Pakistan
}

Tanveer Anjum Chaudhry

Aga Khan University, tanveer.chaudhry@aku.edu

Farzeen Khalid Hashmi

Aga Khan University

Muhammad Sohail Salat

Aga Khan University

Qazi Assad khan

Aga Khan University

Abdul Ahad

Aga Khan University

See next page for additional authors

Follow this and additional works at: https://ecommons.aku.edu/pakistan_fhs_mc_surg_surg

Part of the Ophthalmology Commons, and the Surgery Commons

\section{Recommended Citation}

Chaudhry, T., Hashmi, F., Salat, M., khan, Q. Ahad, A., Taqui, A., Syed, R., Ahmad, K. (2014). Retinopathy of prematurity: an evaluation of existing screening criteria in Pakistan. British Journal of Ophthalmology, 98(3), 298-301.

Available at: https://ecommons.aku.edu/pakistan_fhs_mc_surg_surg/351 


\section{Authors}

Tanveer Anjum Chaudhry, Farzeen Khalid Hashmi, Muhammad Sohail Salat, Qazi Assad khan, Abdul Ahad, Ather M Taqui, Reema Syed, and Khabir Ahmad 


\title{
Retinopathy of prematurity: an evaluation of existing screening criteria in Pakistan
}

\author{
Tanveer Anjum Chaudhry, ${ }^{1}$ Farzeen Khalid Hashmi, ${ }^{1}$ Muhammad Sohail Salat, ${ }^{2}$ \\ Qazi Assad Khan, ${ }^{1}$ Abdul Ahad, ${ }^{1}$ Ather M Taqui, ${ }^{1}$ Reema Syed, ${ }^{1}$ Khabir Ahmad ${ }^{1,3}$
}

\begin{abstract}
${ }^{1}$ Section of Ophthalmology, Department of Surgery, Aga Khan University, Karachi,

Pakistan

${ }^{2}$ Department of Paediatrics and Child Health, Aga Khan University, Karachi, Pakistan ${ }^{3}$ Office of Surgical Research Department of Surgery, Aga Khan University, Karachi, Pakistan
\end{abstract}

\section{Correspondence to} Dr Tanveer Anjum Chaudhry, Section of Ophthalmology, Department of Surgery, Aga Khan University, Stadium Road, P.O Box 3500, Karachi-74800, Pakistan;

tanveer.chaudhry@aku.edu

Received 16 July 2013 Revised 12 November 2013 Accepted 20 November 2013 Published Online First 16 December 2013

\section{CrossMark}

To cite: Chaudhry TA, Hashmi FK, Salat MS, et al. $\mathrm{Br} J$ Ophthalmol 2014;98:298-301.

\section{ABSTRACT}

Aim To evaluate if broadening the criteria for retinopathy of prematurity (ROP) screening to include babies with gestational age $\geq 32$ weeks and/or birth weight $\geq 1500 \mathrm{~g}$, would have an impact on the number of babies diagnosed as having ROP.

Methods A prospective cohort study was carried out at the Aga Khan University Hospital, Karachi, Pakistan. Infants with gestational age $\leq 35$ weeks or birth weight $\leq 2000 \mathrm{~g}$ born in this hospital from May 2010 to December 2012 were screened for the presence of ROP 4-6 weeks after birth. Subsequent examinations were performed at intervals based on the findings of initial eye examinations. Infants diagnosed as having ROP were treated with argon laser therapy. Neonatal risk factors were also assessed. Cumulative incidence of ROP was calculated for babies falling within and outside current screening criteria. Multivariate logistic regression analysis was performed to examine the predictors of ROP.

Results A total of 301 infants were screened: $27(9 \%)$ babies developed ROP, of which 19 had stage 3 ROP or worse. None of the babies falling outside the current screening criteria developed ROP. The incidence of ROP in the infants meeting the current screening criteria was $11.5 \%$. Multivariate logistic regression analysis showed that only gestational age (adjusted relative risk 0.774 , $95 \% \mathrm{Cl} 0.603$ to 0.994 ) was independently associated with the development of ROP.

Conclusions In our population ROP was not seen to occur in infants older than 32 weeks gestational age and/or weighing more than $1500 \mathrm{~g}$.

\section{INTRODUCTION}

Retinopathy of prematurity (ROP) is a major avoidable cause of blindness in children. ${ }^{1}$ In developed countries such as the USA, it is the second most common cause of childhood blindness. ${ }^{2}$ Gilbert $e t a l^{3}$ suggest that heavier and more mature infants are developing severe ROP in countries with low or moderate levels of development compared with developed countries. ROP is emerging as an important cause of childhood blindness in developing countries because of significant improvement in survival rates of premature and low birthweight infants. However, there is a lack of awareness of the disease process and its screening criteria, compounded by a lack of skilled human resources to care for babies at risk of ROP. ${ }^{4}$

Research from several developing countries, including India and China, has shown that the international screening criteria for ROP-gestational age $\leq 32$ weeks and/or birth weight $\leq 1500 \mathrm{~g}$-might not be entirely applicable in this developing part of the world. ${ }^{5}{ }^{6}$ Babies as heavy as $2000 \mathrm{~g}$ at birth and as mature as 35 weeks have been found to develop ROP $^{6-8}$ Several investigators conclude that a significant proportion of ROP cases would have been missed had they used the recommended screening criteria, urging the need for development of regionspecific screening guidelines. ${ }^{9}$ Hence, we decided to conduct a study to determine if broadening the criteria for ROP screening would have an impact on the number of babies diagnosed as having ROP.

\section{METHODS}

All infants-gestational age $\leq 35$ weeks and birth weight $\leq 2000 \mathrm{~g}$ - born at the Aga Khan University Hospital (AKUH), Karachi, from May 2010 to December 2012 were screened for the presence of ROP. The study was approved by the Ethical Review Committee of Aga Khan University, Karachi. Informed consent was obtained from the parents. Data were collected prospectively on gestational age, birth weight, postnatal age, neonatal illnesses (eg, respiratory distress syndrome, sepsis and apnoea) and treatment received (eg, supplemental oxygen, phototherapy, blood transfusions and surfactant therapy).

All infants meeting the screening criteria were scheduled for their first examination between 4 and 6 weeks of life. Dilated fundus examinations were carried out in the clinic or neonatal intensive care unit (NICU) under topical anaesthesia by the consultant ophthalmologist (TAC). Tropicamide $(0.5 \%)$ and phenylephrine $(2.5 \%)$ eye drops were administered three times, 15 min apart, before each examination. Binocular indirect ophthalmoscopy was performed using a 20D and 30D lens. Lid speculum and scleral depressors were used to ensure adequate examination.

The 'International Classification of ROP' guidelines were used to record stage of the disease, location by zone, signs of plus disease and signs of regression. ${ }^{10}$ Babies with no ROP were examined at 2-weekly intervals until they reached 40 weeks post-conception age. Babies with stage 1 and 2 disease were followed up weekly to see if disease regressed or if it progressed to stage 3, in which case treatment was then offered. Infants with stage 3 ROP were treated with argon laser, with or without intravitreal injections of bevacizumab, within $72 \mathrm{~h}$ of diagnosis and followed weekly.

The termination of acute retinal screening examinations was based on the latest guidelines by the American Academy of Pediatrics (AAP), American Academy of Ophthalmology and American Association for Pediatric Ophthalmology and Strabismus. ${ }^{5}$ All data was analysed using IBM SPSS Statistics (V.19, SPSS Inc., an IBM company, 
Armonk, New York, USA). Data for gestational age and birth weight for those who did and did not develop ROP were expressed in the form of mean \pm SD values. Proportions were calculated for categorical variables. The presence of risk factors among those with and without ROP were tested for statistical significance using the $\chi^{2}$ test or univariate binary logistic regression. Independent variables that were associated with ROP with $\mathrm{p} \leq 0.2$ were included in the multivariate binary logistic regression to identify the independent predictors of ROP. A p value $<0.05$ was considered statistically significant.

\section{RESULTS}

From April 2010 to December 2012, a total of 424 babies born at the AKUH fulfilled the eligibility criteria and their parents were invited to allow their participation in the study. Of these, 30 died while in the neonatal intensive care unit and 93 patients did not attend the first scheduled appointment. A total of 301 babies were examined; 163 (54.2\%) were boys. The mean $( \pm \mathrm{SD})$ gestational age of study subjects was $31.2 \pm 2.3$ weeks and the mean birth weight was $1505 \pm 427 \mathrm{~g}$ (table 1). Overall, $9 \%$ (27/301) babies were found to have ROP (table 2). Of 66 infants falling outside the current screening criteria (ie, GA $\leq 32$ weeks \& BW $\leq 1500 \mathrm{~g}$ ), none developed ROP. Further analysis included only those infants who met the international screening criteria for ROP $(n=235)$. Overall, 11.5\% (27/235) babies developed ROP (table 3). Of those with ROP, 18 (66.7\%) had stage 3 and 1 had stage 4 disease. The mean number of examinations was $2.06 \pm 1.47$. Overall $93.7 \%$ babies were examined until they reached 40 weeks post-conception age or were fully vascularised.

In the univariate analysis, factors significantly associated with ROP included birth weight, gestational age, supplemental oxygen, surfactant therapy, septicaemia, birth apnoea, blood transfusions and respiratory distress syndrome (table 4). Except supplemental oxygen, all other predictors were included in the multivariate analysis, which showed only gestational age as an independent predictor of ROP (adjusted relative risk 0.774, 95\% CI 0.603 to 0.994 ). All 19 babies with stage 3 ROP or

Table 1 Demographic and clinical characteristics of newborn babies enrolled in the study $(n=301)$

\begin{tabular}{llrr}
\hline Characteristic & & Count & $\%$ \\
\hline \multirow{2}{*}{ Gender } & Male & 163 & 54.2 \\
& Female & 138 & 45.8 \\
& Total & 301 & 100.0 \\
Supplemental oxygen if given & Yes & 228 & 75.7 \\
& No & 73 & 24.3 \\
Surfactant & Yes & 71 & 23.6 \\
& No & 230 & 76.4 \\
Septicaemia & Yes & 80 & 26.6 \\
& No & 221 & 73.4 \\
Episode of birth apnoea & Yes & 57 & 18.9 \\
& No & 244 & 81.1 \\
Blood transfusions & Yes & 84 & 27.9 \\
\multirow{2}{*}{ Phototherapy for neonatal jaundice } & No & 217 & 72.1 \\
& Yes & 214 & 71.1 \\
Respiratory distress syndrome & No & 87 & 28.9 \\
& Yes & 33 & 11.0 \\
\hline
\end{tabular}

All values are reported as counts and percentages unless noted otherwise. Mean \pm SD gestational age was $31.2 \pm 2.3$ weeks, mean \pm SD birth weight was $1505 \pm 427 \mathrm{~g}$.
Table 2 Risk of ROP among premature infants (gestational age $\leq 35$ weeks and birth weight $\leq 2000 \mathrm{~g}$ ) included in the study $(\mathrm{n}=301)$

\begin{tabular}{|c|c|c|c|c|}
\hline \multirow[b]{2}{*}{ Variable } & \multirow{2}{*}{$\begin{array}{l}\text { Examined } \\
\text { Count }\end{array}$} & \multicolumn{2}{|c|}{ Infants with ROP } & \multirow[b]{2}{*}{ p Value* } \\
\hline & & Count & $\%$ & \\
\hline Overall & 301 & 27 & 9.0 & \\
\hline Gender & & & & 0.289 \\
\hline Male & 163 & 12 & 7.4 & \\
\hline Female & 138 & 15 & 10.9 & \\
\hline Supplemental oxygen & & & & 0.002 \\
\hline Yes & 228 & 27 & 11.8 & \\
\hline No & 73 & 0 & 0 & \\
\hline Surfactant & & & & $<0.001$ \\
\hline Yes & 71 & 19 & 26.8 & \\
\hline No & 230 & 8 & 3.5 & \\
\hline Septicaemia & & & & $<0.001$ \\
\hline Yes & 80 & 15 & 18.8 & \\
\hline No & 221 & 12 & 5.4 & \\
\hline Birth apnoea & & & & $<0.001$ \\
\hline Yes & 57 & 13 & 22.8 & \\
\hline No & 244 & 14 & 5.7 & \\
\hline Blood transfusions & & & & $<0.001$ \\
\hline Yes & 84 & 21 & 25.0 & \\
\hline No & 217 & 6 & 2.8 & \\
\hline Phototherapy & & & & 0.091 \\
\hline Yes & 214 & 23 & 10.7 & \\
\hline No & 87 & 4 & 4.6 & \\
\hline Respiratory distress syndrome & & & & 0.009 \\
\hline Yes & 33 & 7 & 21.2 & \\
\hline No & 268 & 20 & 7.5 & \\
\hline $\begin{array}{l}\text { Meeting international screening } \\
\text { criteria }\end{array}$ & & & & 0.004 \\
\hline Yes & 235 & 27 & 11.5 & \\
\hline No & 66 & 0 & 0.0 & \\
\hline
\end{tabular}

worse were treated, of whom 16 received laser and intravitreal bevacizumab injection and 3 received laser treatment alone.

\section{DISCUSSION}

Contrary to the findings of several previous studies in lowincome countries, our study showed that none of the infants falling outside the current screening criteria used across the world (ie, gestational age $\leq 32$ weeks and/or BW $\leq 1500$ g) developed ROP.

Studies from India, China, Saudi Arabia and Turkey suggested that a significant proportion of babies requiring ROP treatment might have been missed had they used a narrower screening criterion. ${ }^{6}{ }^{11-13}$ In light of such data, we decided to broaden our screening criteria. However, of 66 infants (GA > 32 weeks \& BW $>1500 \mathrm{~g}$ ) in our study, none developed ROP. It remains unclear how many babies of this weight and age need to be screened to detect one additional case of ROP and whether these estimates would differ in different settings.

As part of our study, we also identified factors that could increase the risk of such babies for developing ROP. Gestational age emerged as independent risk factors for the development of ROP. It is also important to mention that determination of correct gestational age of a baby is also a significant challenge in 
Table 3 Risk of ROP among premature infants with gestational age $\leq 32$ weeks and birth weight $\leq 1500 \mathrm{~g}(\mathrm{n}=235)$

\begin{tabular}{|c|c|c|c|c|}
\hline & Fxamined & Infants & ROP & \\
\hline & Count & Count & $\%$ & p Value* \\
\hline Overall & 235 & 27 & 11.5 & \\
\hline Gender & & & & 0.383 \\
\hline Male & 123 & 12 & 9.8 & \\
\hline Female & 112 & 15 & 13.4 & \\
\hline Supplemental oxygen & & & & 0.014 \\
\hline Yes & 196 & 27 & 13.8 & \\
\hline No & 39 & 0 & .0 & \\
\hline Surfactant & & & & $<0.001$ \\
\hline Yes & 67 & 19 & 28.4 & \\
\hline No & 168 & 8 & 4.8 & \\
\hline Septicaemia & & & & $<0.003$ \\
\hline Yes & 72 & 15 & 20.8 & \\
\hline No & 163 & 12 & 7.4 & \\
\hline Birth apnoea & & & & $<0.001$ \\
\hline Yes & 49 & 13 & 26.5 & \\
\hline No & 186 & 14 & 7.5 & \\
\hline Blood transfusions & & & & $<0.001$ \\
\hline Yes & 75 & 21 & 28.0 & \\
\hline No & 160 & 6 & 3.8 & \\
\hline Phototherapy & & & & 0.135 \\
\hline Yes & 172 & 23 & 13.4 & \\
\hline No & 63 & 4 & 6.3 & \\
\hline Respiratory distress syndrome & & & & 0.006 \\
\hline Yes & 25 & 7 & 28.0 & \\
\hline No & 210 & 20 & 9.5 & \\
\hline
\end{tabular}

developing countries especially among less educated. Incorrect measure of GA may have resulted in misclassification of risk in this study as well as other studies.

The incidence of ROP in our study (11.5\%) is much lower than that reported in several previous studies. A possible explanation for these variations, besides genetics, could be the relative distribution of extremely premature babies and distribution of ROP risk factors.

Threshold ROP (stage 3 or worse) was seen in 19 of the 27 babies (70.4\%) who developed ROP. A study from India also reported threshold disease in $62 / 138(45 \%)$ babies. $^{6}$

A limitation of our study was that it looked at ROP incidence in just one hospital at a major Pakistan University with good neonatal care. Things may be very different at smaller hospitals in the country where neonatal care is not as advanced. Future studies should include multiple high-volume centres to increase generalisability. Patient compliance with regular follow-up examinations was a limitation of our study. Reasons for low compliance likely include lack of understanding of the seriousness of ROP as well as the financial constraints of the patients' families. Lack of appropriate counselling of parents by paediatricians/ neonatologists regarding the need for ophthalmic examination in at-risk infants continues to be a factor for failure to have their babies screened. Thus, we continue to see cases where patients seek medical care only when the disease has reached an irreversible stage with loss of red reflex and permanent loss of vision.

Our current screening criteria adopted from the guidelines set by the AAP, the American Association for Pediatric Ophthalmology and Strabismus, and the American Academy of Ophthalmology appear appropriate for the clinical setting of ROP screening in Pakistan. However, a larger multicentre study is needed to determine how many babies above this criterion

Table 4 Univariate and multivariate analysis of factors associated with the risk of ROP among premature infants with gestational age $\leq 32$ weeks and birth weight $\leq 1500 \mathrm{~g}(\mathrm{n}=235)$

\begin{tabular}{|c|c|c|c|c|}
\hline & Crude relative risk & p Value & Adjusted relative risk & p Value \\
\hline Birth weight & 0.996 (0.994 to 0.998$)$ & $<0.001$ & $0.999(0.996$ to 1.001$)$ & 0.178 \\
\hline Gestational age & $0.589(0.501$ to 0.691$)$ & $<0.001$ & 0.774 (0.603 to 0.994$)$ & 0.044 \\
\hline Surfactant & & $<0.001$ & & 0.261 \\
\hline Yes & 5.955 (2.607 to 13.603$)$ & & $1.778(0.651$ to 4.854$)$ & \\
\hline No & 1.0 & & 1.0 & \\
\hline Septicaemia & & 0.007 & & 0.668 \\
\hline Yes & 2.830 (1.325 to 6.046$)$ & & 1.206 (0.513 to 2.832$)$ & \\
\hline No & 1.0 & & 1.0 & \\
\hline Birth apnoea & & 0.001 & & 0.209 \\
\hline Yes & 3.525 (1.657 to 7.499$)$ & & 1.723 (0.737 to 4.029$)$ & \\
\hline No & 1.0 & & 1.0 & \\
\hline Blood transfusions & & $<0.001$ & & 0.349 \\
\hline Yes & 7.467 (3.014 to 18.499$)$ & & $1.757(0.540$ to 5.721$)$ & \\
\hline No & 1.0 & & 1.0 & \\
\hline Phototherapy & & 0.169 & & 0.951 \\
\hline Yes & 2.106 (0.728 to 6.090$)$ & & $0.963(0.292$ to 3.183$)$ & \\
\hline No & 1.0 & & 1.0 & \\
\hline Respiratory distress syndrome & & 0.014 & & 0.714 \\
\hline Yes & 2.940 (1.243 to 6.953$)$ & & $1.194(0.464$ to 3.071$)$ & \\
\hline No & 1.0 & & 1.0 & \\
\hline
\end{tabular}


need to be screened to detect one additional case of ROP and how cost effective such a programme will be.

Acknowledgements The authors wish to acknowledge the generous financial support of URC AKU, and the assistance of Prof Anwar Ali Siddiqui, Tabinda Ahmed, Wajiha Koomal, Iqbal Azam, and all NICU staff at AKUH.

Contributors AMT, RS, TAC, KA and MSS conceived the study. FKH, QAK and AA implemented the study which included data collection, entry and cleaning. KA analysed the data. FKH, TAC and KA wrote the manuscript. All authors reviewed and approved the final draft.

Funding This research project was funded through a research grant by the University Research Counsel of the Aga Khan University, Karachi (grant number: 081014SUR)

Competing interests None.

Ethics approval Ethical Review Committee of Aga Khan University, Karachi.

Provenance and peer review Not commissioned; externally peer reviewed.

\section{REFERENCES}

1 Gilbert C, Foster A. Childhood blindness in the context of VISION 2020-the right to sight. Bull World Health Organ 2001;79:227-32.

2 Steinkuller PG, Du L, Gilbert C, et al. Childhood blindness. J AAPOS 1999;3:26-32.

3 Gilbert $\mathrm{C}$, Fielder $\mathrm{A}$, Gordillo $\mathrm{L}$, et al. Characteristics of infants with severe retinopathy of prematurity in countries with low, moderate, and high levels of development: implications for screening programs. Pediatrics 2005;115:e518-25.
4 Hashmi FK, Chaudhry TA, Ahmad K. An evaluation of referral system for retinopathy of prematurity in leading health centers across Karachi, Pakistan. J Pak Med Assoc 2010:60:840-4.

5 Screening examination of premature infants for retinopathy of prematurity. Pediatrics 2006:117:572-6.

6 Vinekar A, Dogra MR, Sangtam T, et al. Retinopathy of prematurity in Asian Indian babies weighing greater than 1250 grams at birth: ten year data from a tertiary care center in a developing country. Indian I Ophthalmol 2007;55:331-6.

7 Jalali S, Matalia J, Hussain A, et al. Modification of screening criteria for retinopathy of prematurity in India and other middle-income countries. Am J Ophthalmol 2006;141:966-8.

8 Chiang MF, Arons RR, Flynn JT, et al. Incidence of retinopathy of prematurity from 1996 to 2000: analysis of a comprehensive New York state patient database. Ophthalmology 2004;111:1317-25.

9 Chen Y, Li X. Characteristics of severe retinopathy of prematurity patients in China: a repeat of the first epidemic? Br J Ophthalmol 2006;90:268-71.

10 The International Committee for the Classification of Retinopathy of Prematurity. The International Classification of Retinopathy of Prematurity revisited. Arch Ophthalmol 2005;123:991-9.

11 Hungi B, Vinekar A, Datti N, et al. Retinopathy of prematurity in a rural neonatal intensive care unit in South India-a prospective study. Indian I Pediatr 2012;79:911-15

12 Binkhathlan AA, Almahmoud LA, Saleh MJ, et al. Retinopathy of prematurity in Saudi Arabia: incidence, risk factors, and the applicability of current screening criteria. Br J Ophthalmol 2008;92:167-9.

13 Araz-Ersan B, Kir N, Akarcay K, et al. Epidemiological analysis of retinopathy of prematurity in a referral centre in Turkey. Br J Ophthalmol 2012;97:15-17. 